\title{
PENGARUH JOB EMBEDDEDNESS DAN WORK ENGAGEMENT TERHADAP INTENSI TURNOVER
}

\author{
Ayu Lestari \\ Mulia Sari Dewi \\ UIN Syarif Hidayatullah Jakarta \\ muliasaridewi@yahoo.com
}

\begin{abstract}
Human resources is a major asset that can support the achievement of company objectives. Therefore, the company continually strives to develop and maintain employees in order not to affect the movement of employees (turnover). This study aims to examine the effect of job embeddedness and workengagement on turnover intention. These samples included 200 employees of PT Medco E \& P Indonesia taken with nonprobability sampling technique. Test the validity of the instrument turnover intention, scale job embeddedness, and Utrecht Work Engagement Scale (Uwes) was done by using confirmatory factor analysis (CFA). Results of multiple regression analysis is that there is significant influence job embeddedness and work engagement against turnover intention with $R=0.43$. There are two dimensions of job embeddedness of variables that provide significant and negative effect terhadapintensi turnover, the fit organization and sacrifice organization.
\end{abstract}

Keywords: Turnover Intention, Job Embeddedness, Work Engagement.

\begin{abstract}
Abstrak
Sumber daya manusia merupakan aset utama yang dapat mendukung tercapainya tujuan perusahaan. Oleh sebab itu, perusahaan terus menerus berupaya untuk mengembangkan dan mempertahankan karyawannya agar tidak berdampak pada perpindahan karyawan (turnover). Penelitian ini bertujuan menguji pengaruh job embeddedness dan workengagement terhadap intensi turnover. Sampel penelitian berjumlah 200 orang karyawan PT Medco E\&P Indonesia yang diambil dengan teknik nonprobability sampling. Uji validitas dengan teknik Confirmatory Factor Analysis (CFA) dilakukan terlebih dahulu terhadap instrumen intensi turnover, skala job embeddedness, dan Utrecht Work Engagement Scale (UWES). Melaui teknik analisis regresi berganda diperoleh hasil terdapat pengaruh yang signifikan job embeddedness dan work engagement terhadap intensi turnover dengan $R=0,43$. Terdapat dua dimensi dari variabel job embeddedness yang memberikan pengaruh signifikan dan negatif terhadap intensi turnover, yaitu fit organization dan sacrifice organization.
\end{abstract}

Kata Kunci: Intensi Turnover, Job Embeddedness, Keterikatan Kerja. 


\section{PENDAHULUAN}

Sumber daya manusia merupakan aset utama yang dapat mendukung tercapainya tujuan perusahaan. Hal tersebut yang membuat perusahaan menyadari bahwa karyawan sangat mempengaruhi efisiensi dan efektivitas perusahaan. Oleh sebab itu, perusahaan harus memprioritaskan upaya untuk mengembangkan dan mempertahankan karyawan yang dapat mendukung tercapainya tujuan perusahaan agar tidak berdampak pada perpindahan karyawan (turnover).

Ada kalanya pergantian karyawan karena turnover memberi dampak yang positif bagi suatu organisasi. Terutama apabila pekerja-pekerja yang pergi adalah mereka yang berkinerja rendah, individu yang kurang dapat diandalkan, atau mereka yang mengganggu rekan kerja (Mathis \& Jackson, 2006). Namun, sebagian besar turnover karyawan justru memberikan dampak negatif terhadap organisasi. Diantaranya, ketika perusahaan merekrut seorang pegawai baru untuk menggantikan mereka yang keluar, biaya yang dikeluarkan tidaklah sedikit. Mulai dari biaya perekrutan yang terdiri atas biaya pemasangan iklan, penggajian perekrut, bahkan beberapa perusahaan yang menerima pelamar dari lokasi yang jauh biasanya membiayai perjalanan dan akomodasi pelamar. Selain itu, tentunya akan ada pelatihan-pelatihan yang sesuai dengan job description agar perkerjaan yang dilakukan sesuai dengan standar perusahaan. Dengan demikian, jika karyawan mengundurkan diri, terutama karyawan dengan high performers, maka perusahaan akan mengalami kerugian secara finansial dan waktu (Adhitiawan, 2014).

Tingginya turnover karyawan tidak hanya melibatkan biaya yang harus dikeluarkan untuk melakukan rekrutmen dan pelatihan lagi tetapi juga menyebabkan perusahaan kehilangan sumber keterampilan, pengetahuan dan pengalaman yang akan berakibat negatif pada moril karyawan. (Ponnu \& Chuah, 2010). Dimana karyawan yang bertahan harus menangani tanggungjawab ekstra atau tugas-tugas yang sebelumnya tidak pernah mereka lakukan, tanpa adanya keterampilan dan ketidakmampuan dalam menangani permasalahan (Puji, 2014). Kehilangan karyawan yang high performers juga dapat mengurangi kemampuan organisasi untuk berinovasi (Radjasa, 2012).

Karyawan juga merupakan ujung tombak yang langsung berinteraksi dengan para klien atau relasi. Merekalah yang membuat para klien memutuskan untuk bekerjasama lagi atau tidak. Oleh sebab itu, kehilangan 
karyawan yang mampu memberikan pelayanan terbaik kepada klien akan sangat merugikan karena dapat menyebabkan perusahaan kehilangan klien atau relasi (Adhitiawan, 2014).

Selain itu, jika karyawan di suatu perusahaan selalu mengalami pergantian maka akan menyebabkan ketidakstabilan bagi karyawan serta klien. Hal tersebut dikarenakan klien harus selalu berhadapan dengan orang-orang baru, sehingga perubahan-perubahan tersebut akan memberikan tampilan ketidakstabilan yang terdapat di perusahaan (Puji, 2014).

Selanjutnya, karyawan high performers adalah yang paling memahami apa yang terjadi di perusahaan. Mereka memegang informasi jauh lebih banyak dibandingkan pegawai-pegawai yang berkinerja rendah atau biasa. Jika karyawan tersebut berpindah ke perusahaan kompetitor dan membocorkan teknologi yang sedang dikembangkan oleh perusahaan, maka perusahaan akan sangat merugi. Hal tersebut dikarenakan perusahaan kompetitor dapat mengetahui bagaimana perusahaan menyusun anggaran dan harga untuk memenangkan tender proyek bernilai milyaran rupiah (Adhitiawan, 2014).

Ada beberapa hal yang menyebabkan karyawan yang memiliki potensi tinggi memilih untuk meninggakan pekerjaannya. Gallup Organization melakukan survei terhadap satu juta karyawan dan delapan puluh ribu manajer yang kemudian di publikasikan dalam sebuah buku berjudul — First Break All the Rules\| (dalam Kristianto, 2009). Hasil survei menunjukkan bahwa jika orang- orang yang memiliki potensi tinggi meninggalkan perusahaan, maka lihatlah atasan tertinggi di departemen mereka. Lebih dari alasan apapun, dia adalah alasan orang bertahan dan berkembang dalam organisasi. Atasan pula yang menjadi adalah alasan mengapa mereka berhenti dari pekerjaan dengan membawa pengetahuan, pengalaman, dan relasi bersama mereka.

Di sisi lain, kebutuhan utama seorang karyawan tidak terlalu terkait dengan uang, namun lebih terkait dengan bagaimana dia diperlakukan dan dihargai (Kristianto, 2009). Para manajer bisa membuat karyawan stres dengan cara yang berbeda-beda. Misalnya dengan terlalu mengontrol, terlalu curiga, terlalu mencampuri, sok tahu, dan terlalu mengecam (Kristianto, 2009). Para manajer terkadang lupa bahwa para pekerja bukanlah aset tetap, mereka adalah agen bebas. Jika hal ini berlangsung terlalu lama, seorang karyawan akan memutuskan untuk berhenti dari pekerjaannya dan membuat rasio turnover meningkat. 
Berdasarkan hasil wawancara yang telah dilakukan peneliti kepada seorang staff PT. Medco Energy yaitu Bapak Sayuthi mengungkapkan bahwa masih banyak karyawan yang resign setiap tahunnya di PT. Medco Energy yang berlokasi di SCBD (Sudirman Central Bussiness District). Adapun faktor utama yang membuat seseorang ingin keluar dari pekerjaannya adalah masalah kenyamanan. Kenyamanan tersebut dipengaruhi oleh sikap atasan terhadap bawahannya. Menurutnya, meskipun seseorang tersebut memiliki gaji besar tapi jika tidak ada kenyamanan yang didapat terutama dari atasan maka seseorang tersebut akan lebih memilih untuk meninggalkan pekerjaannya. Selain itu, ketidaknyamanan yang dirasakan juga dapat berupa jauhnya jarak tempuh antara tempat tinggal dan tempatnya bekerja. Banyak karyawan memilih mencari pekerjaan lain yang letaknya strategis dengan tempat tinggalnya.

Dari pemaparan diatas, terlihat bahwa turnover karyawan merupakan salah satu tantangan sumber daya terbesar yang dihadapi oleh organisasi akhirakhir ini (Ponnu \& Chuah, 2010). Mobley (1977) menyatakan bahwa sebelum karyawan memutuskan keluar dari organisasi maka ia akan melewati beberapa tahapan dalam proses pengambilan keputusan. Dengan demikian, sebelum seseorang keluar dari organisasi, ia akan memiliki keinginan untuk berhenti dari pekerjaannya dan menjalani beberapa proses kognitif yang kemudian mengarahkannya kepada perilaku aktual turnover. Dalam konstruk psikologi, istilah dari keinginan karyawan untuk keluar dari pekerjaannya disebut dengan intensi turnover. Menurut Sousa-Poza dan Henneberger (2004) intensi turnover merupakan manifestasi dari (hubungan) kemungkinan seseorang itu akan berganti pekerjaan pada satu periode waktu tertentu. Oleh sebab itu, intensi turnover yang dimiiki karyawan akan mengarah pada perilaku turnover.

Hingga saat ini telah banyak studi mengenai alasan karyawan meninggalkan atau setidaknya berpikir untuk meninggalkan pekerjaan. Pada umumnya, penelitian terdahulu (March \& Simon, 1958; Mobley, 1977; Steers \& Mowday, 1981; Price \& Mueller,1981; Hom \& Griffeth, 1995 dalam Mitchell, et.al 2001) menggunakan variabel prediktor yang meliputi dua kategori utama untuk memprediksi intensi turnover. Kategori pertama, menekankan pada sikap kerja (kepuasan kerja dan komitmen organisasi). Sedangkan kategori kedua, menekankan pada kemudahan dari pergerakan karyawan (yang dicerminkan pada alternatif pekerjaan dan perilaku pencarian pekerjaan). 
Selanjutnya, penelitian yang dilakukan oleh Mitchell, Holtom, Lee, Sablynski, dan Erez (2001) mengembangkan variabel yang mengidentifikasi faktor on-the-job dan off- the-job yang dapat mempengaruhi intensi turnover. Sekumpulan faktor on-the-job dan off-the-job yang mempengaruhi seseorang bertahan atau keluar dari pekerjaannya disebut dengan job embeddedness (Mitchel, et.al. 2001). Faktor-faktor yang termuat dalam variabel job embeddedness terdiri dari link, fit, dan sacrifice yang dilihat dari segi pekerjaan itu sendiri (on-the-job) dan hal-hal diluar pekerjaannya (off-the-job) seperti komunitas atau lingkungan sosial yang dimiliki individu tersebut (Mitchel, et.al. 2001). Berdasarkan hasil penelitian yang dilakukan oleh Mitchell, et.al. (2001); Halbesleben dan Wheeler, (2008); Takawira, Coetzee, dan Schreuder (2014) terlihat bahwa job embeddedness memiliki korelasi negatif terhadap intensi turnover. Dengan demikian, semakin tinggi job embeddedness yang dimiliki seseorang semakin rendah niat untuk meninggalkan pekerjaan tersebut dan sebaliknya.

Selain job embeddedness, faktor lain yang dapat mempengaruhi intensi turnover adalah work engagement. Work engagement didefinisikan sebagai sebuah motivasi dan pusat pikiran positif yang berhubungan dengan pekerjaan. Work engagement dicirikan dengan semangat, dedikasi dan penghayatan dalam pekerjaan (Schaufeli, Salanova, Gonzales-Roma, \& Bakker, 2002). Work engagement merupakan keterikatan psikologis seseorang terhadap pekerjaannya (Takawira, et.al., 2014). Menurut Saks (2006), work engagement terkait dengan sikap individu, niat dan perilaku. Oleh karena itu, karyawan cenderung lebih melekat terhadap organisasi mereka dan akan memiliki kecenderungan yang rendah untuk meninggalkan organisasi. Pandangan ini didukung oleh beberapa peneliti yang menemukan bahwa work engagement berhubungan negatif dengan intensi turnover (Du Plooy \& Roodt, 2010; Halbesleben \& Wheeler, 2008; Takawira, et.al. 2014).

Penelitian terdahulu menunjukkan bahwa job embeddedness dan work engagement telah muncul di dunia kerja saat ini sebagai konstruksi yang secara signifikan dapat mempengaruhi intensi turnover pada karyawan (Halbesleben $\&$ Wheeler, 2008). Hasil penelitian yang dilakukan menunjukkan bahwa job embeddedness dan work engagement memiliki pengaruh yang negatif terhadap intensi turnover (Halbesleben \& Wheeler, 2008; Takawira, et.al. 2014). Dengan demikian, semakin tinggi job embeddedness dan work engagement yang dimiliki seseorang, maka semakin rendah keinginannya untuk meninggakan pekerjaannya saat ini. 
Oleh sebab itu, dalam penelitian ini bukan hanya meneliti faktor didalam pekerjaan (on-the-job) tetapi juga faktor diluar pekerjaan (off-the-job) yang mempengaruhi intensi turnover seseorang. Selain itu, dalam penelitian ini juga meneliti sejauh mana level keterikatan karyawan pada pekerjaannya terhadap keinginannya untuk berhenti dari pekerjaannya saat ini yang tercermin dalam kondisi psikologis yang positif selama bekerja. Sehingga penelitian yang akan dilakukan berjudul -Pengaruh job embeddedness dan work engagement terhadap intensi turnover $\|$.

\section{Intensi Turnover}

Mobley (dalam Long, et.al., 2012) merupakan perintis dalam model teoritis turnover yang mengemukakan bagaimana tahapan atau proses pengambilan keputusan sebelum akhirnya terjadi perilaku aktual turnover. Mobley (1977) mendefinisikan intensi tunover sebagai niat seseorang untuk meninggalkan pekerjaannya dengan melalui serangkaian proses pengambilan keputusan. Proses tersebut disertai oleh adanya pemikiran secara aktif dan pencarian alternatif pekerjaan yang lain setelah seseorang mengalami job dissatisfaction. Dengan demikian, sebelum terjadi perilaku aktual turnover, seseorang akan mengalami beberapa tahapan hingga perilaku turnover benar-benar muncul. Berdasarkan model teoritis Mobley (1977), tahapan tersebut disebut dengan proses withdrawal decision.

\section{Job embeddedness}

Job embeddedness adalah sekumpulan faktor yang menyebabkan karyawan bertahan pada pekerjannya yang merupakan konstruk yang mempengaruhi seseorang bertahan atau keluar dari pekerjaannya (Mitchell, et.al., 2001). Faktor-faktor tersebut terdiri dari link, fit, dan sacrifice yang dilihat dari segi pekerjaan itu sendiri (on-the-job) dan hal- hal diluar pekerjaannya (off-the-job) seperti komunitas atau lingkungan sosial yang dimiliki individu tersebut (Mitchel, et.al. 2001).

\section{Work engagement}

Work engagement adalah sebuah motivasi dan pusat pikiran positif yang berhubungan dengan pekerjaan yang dicirikan dengan semangat, dedikasi, dan penghayatan dalam pekerjaan (Schaufeli, et.al., 2002). 


\section{METODE}

Variabel yang ada pada penelitian ini adalah intensi turnover sebagai variabel terikat kemudian job embeddedness dan work engagement sebagai variabel bebas. Penelitian ini menggunakan kuesioner berupa skala likert yang berdasarkan pengembangan teori dari masing-masing variabel. Subjek dalam penelitian ini adalah karyawan PT. Medco E\&P Indonesia sebanyak 200 orang. Metode analisis menggunakan SPSS dan Lisrel.

\section{HASIL}

Hasil uji hipotesis menggunakan teknik analisis regresi berganda adalah sebagai berikut:

\section{Tabel 1}

ANOVA

\begin{tabular}{|c|c|c|c|c|c|}
\hline Model & $\begin{array}{l}\text { Sum of } \\
\text { Souares }\end{array}$ & df & Mean Square & $\mathbf{F}$ & Sig. \\
\hline Regression & 7729.074 & 9 & 858.786 & 16.055 & $0.000^{\mathrm{a}}$ \\
\hline Residual & 10162.839 & 190 & 53.489 & & \\
\hline Total & 17891.913 & 199 & & & \\
\hline
\end{tabular}

Berdasarkan tabel tersebut, diketahui bahwa nilai signifikansi 0.000 dimana taraf signifikansi $5 \%$ atau 0.05. Maka dapat diartikan bahwa ada pengaruh yang signifikan dari link-organization, link-community, fitorganization, fit-community, sacrifice-organization, sacrifice-community, semangat, dedikasi, dan penghayatan dalam pekerjaan terhadap intensi turnover. 
Tabel 2

Koefisien Regresi

\begin{tabular}{lccc}
\hline \multicolumn{1}{c}{ Model } & $\begin{array}{c}\text { Unstandardized } \\
\text { coefficients } \\
\text { B }\end{array}$ & $\begin{array}{c}\text { Standardized } \\
\text { coefficients } \\
\text { Beta }\end{array}$ & Sig. \\
\cline { 3 - 4 } & 94.676 & & \\
\hline 1 (constant) & -.114 & -.118 & 0.000 \\
$\quad$ Link organization & -.070 & -.057 & .397 \\
Link community & -.174 & -.162 & .025 \\
Fit organization & .024 & .022 & .721 \\
Fit community & -.460 & -.422 & .000 \\
Sacrifice organization & .110 & .056 & .356 \\
Sacrifice community & .025 & .025 & .823 \\
Semangat & -.173 & -.176 & .123 \\
Dedikasi & -.061 & -.060 & .537 \\
Penghayatan kerja & & &
\end{tabular}

Keterangan:

a. Dependent Variable: Intensi_turnover

Berdasarkan koefisien regresi pada tabel 2, menunjukkan bahwa persamaan regresi sebagai berikut:

$$
\begin{aligned}
& \text { Intensi turnover }=94.676-0,114 \mathrm{Link} \quad \text { organization } \quad-\quad 0,070 \mathrm{Link} \\
& \text { community - 0,174 Fit organization* + 0,024Fit } \\
& \text { community-0,460 Sacrifice organization* }+0,110 \\
& \text { Sacrifice community }+\quad 0,025 \text { Semangat }-0,173 \\
& \text { Dedikasi - 0,061 Penghayatan kerja. }
\end{aligned}
$$

Pada tabel 2, signifikan atau tidaknya koefisien regresi yang dihasilkan dapat dilihat dari nilai sig pada kolom paling kanan. Apabila $\mathrm{P}<0.05$ maka koefisien regresi yang dihasilkan signifikan pengaruhnya terhadap intensi intensi turnover. Berdasarkan data pada tabel di atas, nampak bahwa hanya fitorganization dan sacrifice-organization yang signifikan sedangkan yang lainnya tidak signifikan. Penjelasan dari nilai koefisien regresi yang diperoleh pada masing-masing IV adalah sebagai berikut:

1. Variabel link organization memiliki nilai signifikansi sebesar 0,085. Karena nilai sig $>0,05$ maka dapat disimpulkan bahwa hipotesis nihil (H0) diterima. Jadi, dapat dikatakan bahwa tidak terdapat pengaruh signifikan link organization terhadap intensi turnover.

2. Variabel link community memiliki nilai signifikansi sebesar 0,397. Karena nilai sig $>0,05$ maka dapat disimpulkan bahwa hipotesis nihil (H0) diterima. Jadi, dapat dikatakan bahwa tidak terdapat pengaruh 
signifikan link community terhadap intensi turnover.

3. Variabel fit organization memiliki nilai koefisien regresi sebesar $-0,174$ dan signifikansi sebesar 0,025 . Karena nilai sig $<0,05$ maka dapat disimpulkan bahwa hipotesis nihil (H0) ditolak. Jadi, dapat dikatakan bahwa terdapat pengaruh yang signifikan dan negatif fit organization terhadap intensi turnover. Artinya, semakin tinggi nilai fit organization seseorang maka semakin rendah intensi turnover.

4. Variabel fit community memiliki nilai signifikansi sebesar 0,721. Karena nilai sig $>0,05$ maka dapat disimpulkan bahwa hipotesis nihil (H0) diterima. Jadi, dapat dikatakan bahwa tidak terdapat pengaruh signifikan fit community terhadap intensi turnover.

5. Variabel sacrifice organization memiliki nilai koefisien regresi sebesar 0,460 dan signifikansi sebesar 0,000 . Karena nilai sig $<0,05$ maka dapat disimpulkan bahwa hipotesis nihil (H0) ditolak. Jadi, dapat dikatakan bahwa terdapat pengaruh yang signifikan dan negatif sacrifice organization terhadap intensi turnover. Artinya, semakin tinggi nilai sacrifice organization seseorang maka semakin rendah intensi turnover.

6. Variabel sacrifice community memiliki nilai signifikansi sebesar 0,356. Karena nilai sig $>0,05$ maka dapat disimpulkan bahwa hipotesis nihil (H0) diterima. Jadi, dapat dikatakan bahwa tidak terdapat pengaruh signifikan sacrifice community terhadap intensi turnover.

7. Variabel semangat memiliki nilai signifikansi sebesar 0,823 . Karena nilai sig $>0,05$ maka dapat disimpulkan bahwa hipotesis nihil (H0) diterima. Jadi, dapat dikatakan bahwa tidak terdapat pengaruh signifikan semangat terhadap intensi turnover.

8. Variabel dedikasi memiliki nilai signifikansi sebesar 0,123 . Karena nilai sig $>0,05$ maka dapat disimpulkan bahwa hipotesis nihil (H0) diterima. Jadi, dapat dikatakan bahwa tidak terdapat pengaruh signifikan dedikasi terhadap intensi turnover.

9. Variabel penghayatan dalam pekerjaan memiliki nilai signifikansi sebesar 0,537. Karena nilai sig $>0,05$ maka dapat disimpulkan bahwa hipotesis nihil (H0) diterima. Jadi, dapat dikatakan bahwa tidak terdapat pengaruh signifikan penghayatan dalam pekerjaan terhadap intensi turnover.

Pada bahasan sebelumnya, dapat diketahui bahwa terdapat dua IV yang memiliki pengaruh signfikan terhadap intensi berwirausaha, yaitu fitorganization dan sacrifice-organization Peneliti juga ingin mengetahui 
bagaimana besaran muatan atau kontribusi dari masing-masing independent variable berpengaruh terhadap intensi turnover, lalu mengurutkannya dari besaran muatan yang paling besar hingga yang paling kecil. Pada akhirnya akan diketahui prediktor mana yang memiliki pengaruh paling besar terhadap intensi berwirausaha. Pada tabel 3 akan dipaparkan besarnya proporsi varians pada intense turnover.

Tabel 3

Proporsi Varian Sumbangan Masing-Masing IV

\begin{tabular}{clcc}
\hline No. & Independent Variabel & R Square & R2 Change \\
\hline 1 & Link organization & 0.008 & 0.008 \\
2 & Link community & 0.008 & 0.000 \\
3 & Fit organization & 0.245 & 0.237 \\
4 & Fit community & 0.247 & 0.002 \\
5 & Sacrifice organization & 0.397 & 0.151 \\
6 & Sacrifice community & 0.401 & 0.003 \\
7 & Semangat & 0.420 & 0.020 \\
8 & Dedikasi & 0.431 & 0.010 \\
9 & Penghayatan kerja & 0.432 & 0.001 \\
\hline
\end{tabular}

Berdasarkan data pada tabel 3 dapat diketahui bahwa urutan prediktor yang memiliki kontribusi terhadap intensi turnover dari yang terbesar hingga yang terkecil adalah fit organization, sacrifice organization, semangat, dedikasi, link organization, sacrifice community, fit community, dan penghayatan kerja. Sementara variabel link community tidak memberikan sumbangan atau pengaruh bagi bervariasinya intensi turnover.

\section{DISKUSI}

Berdasarkan hasil analisis data serta pengujian hipotesis menggunakan perhitungan Anova yang telah dikemukakan pada data sebelumnya, maka kesimpulan yang dapat diambil dari penelitian ini adalah :

1. Terdapat pengaruh yang signifikan job embeddedness dan work engagement terhadap intensi turnover.

2. Dari sembilan variabel bebas, hanya ada dua variabel yang berpengaruh signifikan terrhadap intensi turnover, sedangkan beberapa variabel lainnya tidak berpengaruh secara signifikan. Dimensi job embeddedness yang memberikan pengaruh signifikan dan negatif terhadap intensi turnover adalah variabel fit organization dan sacrifice organization. Sedangkan dimensi work engagement tidak ada yang memberikan 
pengaruh signifikan terhadap intensi turnover.

Berdasarkan penelitian ini, peneliti menyadari bahwa masih terdapat banyak kekurangan di dalamnya. Untuk itu, peneliti memberikan beberapa saran untuk bahan pertimbangan selanjutnya sebagai penyempurnaan penelitian selanjutnya,

1. Pada penelitian selanjutnya, diharapkan dapat menambahkan variabel lain selain variabel yang telah diteliti agar lebih luas dalam gambaran penelitiannya. Seperti variabel stres kerja, komitmen organisasi, kepuasan kerja, dan lain sebagainya.

2. Pada penelitian selanjutnya, sebaiknya dapat menggunakan subjek dari berbagai profesi. Hal itu dikarenakan turnover dapat terjadi di berbagai kalangan profesi.

3. Setiap perusahaan diharapkan dapat melakukan sosialisasi mengenai nilainilai yang diterapkan perusahaan. Hal tersebut ditujukan agar setiap karyawan dapat menyelaraskan antara nilai-nilai pribadi, tujuan karir dan rencana masa depan yang dimiliki dengan budaya perusahaan serta hal-hal yang terkait dengan pekerjaan secara langsung (misalnya, pengetahuan tentang pekerjaan, keterampilan dan kemampuan dalam bekerja). Dengan demikian, dapat tercipta kecocokan antara apa yang ada didalam diri karyawan dengan apa yang diharapkan perusahaan, sehingga dapat menciptakan kenyamanan bagi karyawan dalam bekerja dan keinginan karyawan untuk meninggalkan pekerjaannya pun menjadi rendah.

4. Setiap perusahaan diharapkan dapat memberikan nilai tambah kepada karyawan. Misalnya, memberikan pelatihan, pembelajaran maupun mentoring kepada karyawan secara berkala. Dengan demikian, karyawan akan merasa bahwa diperusahaan tersebut ia mendapatkan banyak ilmu yang membawanya kearah kemajuan. Karyawan akan merasa apa yang didapat di perusahaan tempatnya bekerja tidak ia dapatkan jika ia bekerja di perusahaan lain. Oleh sebab itu, ketika seorang karyawan berpikir untuk meninggalkan pekerjaannya, ia akan merasa banyak resiko ataupun kerugian yang akan diterimanya. Dengan demikian, keinginannya untuk meninggalkan pekerjaannya pun menjadi rendah. 


\section{DAFTAR PUSTAKA}

Adhitiawan, E. (2014). Dampak buruk tingkat pergantian (turnover rate) SDM yang tinggi. Diunduh tanggal 5 Agustus 2015 dari http://www. refinedanalyticsindonesia.com/blog/dampak-buruk-tingkat-pergantianturnover-rate- sdm-yang-tinggi

Du Plooy, J. \& Roodt, G. (2010). Work engagement, burnout and related constructs as predictors of turnover intentions. SA Journal of Industrial Psychology, 36(1), 910- 913.doi:10.4102.

Halbesleben, J.R.B., \& Wheeler, A.R. (2008). The relative roles of engagement and embeddedness in predicting job performance and intentions to leave. Work \& Stress, 22(3), 242-256.doi:10.1080/02678370802383962.

Kristianto, P. (2009). Mailing list migas Indonesia : (oil \& gas) Salahkah saya?. Diunduh tanggal 12 februari 2015 dari https://groups.yahoo.com/neo/groups/Migas_Indonesia/conversati ons/messages/87287

Long, C.S., Ajagbe, M.A., Nor, K.M., \& Suleiman, E.S. (2012). The Approaches to Increase Employees Loyalty: A Review on Employees Turnover Models. Australian Journal of Basic and Applied Sciences, 6(10): 282-291, ISSN 1991-8178

Mathis, R.L., \& Jackson, J.H (2006), Human Resource Management, Edisi Kesepuluh, Prentice Hall, Jakarta.

Mitchell, T.R., Holtom, B.C., Lee, T.W., Sablynski, C.J. \& Erez, M. (2001). Why people stay: Using job embeddedness to predict voluntary turnover. Academy of Management Journal, 44, 1102-1121.

Mobley, W. H. (1977). Intermediate linkages in the relationship between job satisfaction and employee turnover. Journal of Applied Psychology, 62, 237-240.

Ponnu, C. H. and Chuah, C.C. (2010). Organizational commitment, organizational justice and employee turnover in Malaysia. African Journal of Business Management. 4(13), 2676-2692.

Puji, M.S. (2014). Dampak buruk tingkat turnover karyawan yang tinggi. Diunduh tanggal 5 Agustus 2015 dari http://www.bestlife.co.id/lifestyle/the.good.life/dampak.buruk.tingk at.turnover.karyawan.yang.tinggi/004/001/251

Radjasa, S (2012). Hidden cost of employee turnover. Diunduh tanggal 22 Desember 2014 dari http://www.portalhr.com/komunitas/opini/hiddencost-of-employee-turnover/

Schaufeli, W.B., Salanova, M., Gonzalez-Roma, V. \& Bakker, A.B. (2002). The measurement of engagement and burnout: A confirmative analytic approach. Journal of Happiness Studies, 3, 71-92. 
Sousa-Poza, A., \& Henneberger, F. (2002). Analyzing job mobility with job turnover intentions: An international comparative study. Research Institute for Labour Economics and Labour Law, 82, 1-28.

Takawira, N., Coetzee, M., \& Schreuder, D. (2014). Job embeddedness, work engagement and turnover intention of staff in a higher education institution: An exploratory study. SA Journal of Human Resource Management, 12(1), 524-534.doi:10.4102 